\title{
Bacteroides thetaiotaomicron-derived outer membrane vesicles promote regulatory dendritic cell responses in health but not in inflammatory bowel disease
}

Lydia Durant ${ }^{1 *}$ (D) Régis Stentz ${ }^{2 \dagger}$, Alistair Noble ${ }^{1 \dagger}$, Johanne Brooks ${ }^{2,3}$, Nadezhda Gicheva ${ }^{2}$, Durga Reddi ${ }^{1}$, Matthew J. O'Connor ${ }^{1}$, Lesley Hoyles ${ }^{4}$, Anne L. McCartney ${ }^{5}$, Ripple Man ${ }^{6}$, E. Tobias Pring ${ }^{1,6}$, Stella Dilke ${ }^{1,6}$, Philip Hendy ${ }^{1,6}$, Jonathan P. Segal ${ }^{6}$, Dennis N. F. Lim ${ }^{6}$, Ravi Misra ${ }^{6}$, Ailsa L. Hart ${ }^{6}$, Naila Arebi ${ }^{6}$, Simon R. Carding ${ }^{2,3}$ and Stella C. Knight ${ }^{1,6}$

\begin{abstract}
Background: Bacteroides thetaiotaomicron (Bt) is a prominent member of the human intestinal microbiota that, like all gram-negative bacteria, naturally generates nanosized outer membrane vesicles (OMVs) which bud off from the cell surface. Importantly, OMVs can cross the intestinal epithelial barrier to mediate microbe-host cell crosstalk involving both epithelial and immune cells to help maintain intestinal homeostasis. Here, we have examined the interaction between Bt OMVs and blood or colonic mucosa-derived dendritic cells (DC) from healthy individuals and patients with Crohn's disease (CD) or ulcerative colitis (UC).

Results: In healthy individuals, Bt OMVs stimulated significant $(p<0.05)$ IL-10 expression by colonic DC, whereas in peripheral blood-derived DC they also stimulated significant ( $p<0.001$ and $p<0.01$, respectively) expression of IL-6 and the activation marker CD80. Conversely, in UC Bt OMVs were unable to elicit IL-10 expression by colonic DC. There were also reduced numbers of $C D 103^{+} \mathrm{DC}$ in the colon of both UC and CD patients compared to controls, supporting a loss of regulatory DC in both diseases. Furthermore, in CD and UC, Bt OMVs elicited a significantly lower proportion of DC which expressed IL-10 ( $p<0.01$ and $p<0.001$, respectively) in blood compared to controls. These alterations in $\mathrm{DC}$ responses to Bt OMVs were seen in patients with inactive disease, and thus are indicative of intrinsic defects in immune responses to this commensal in inflammatory bowel disease (IBD).
\end{abstract}

Conclusions: Overall, our findings suggest a key role for OMVs generated by the commensal gut bacterium Bt in directing a balanced immune response to constituents of the microbiota locally and systemically during health which is altered in IBD patients.

Keywords: Dendritic cells, Outer membrane vesicles, Bacteroides thetaiotaomicron, Interleukin-10, Inflammatory bowel disease

\footnotetext{
* Correspondence: I.durant@imperial.ac.uk

${ }^{\dagger}$ Régis Stentz and Alistair Noble contributed equally to this work.

'Antigen Presentation Research Group, Imperial College London, Northwick

Park \& St. Mark's Hospital Campus, Watford Rd, Harrow, Greater London HA1

3UJ, UK

Full list of author information is available at the end of the article
}

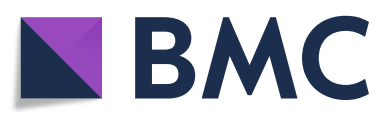

(- The Author(s). 2020 Open Access This article is licensed under a Creative Commons Attribution 4.0 International License, which permits use, sharing, adaptation, distribution and reproduction in any medium or format, as long as you give appropriate credit to the original author(s) and the source, provide a link to the Creative Commons licence, and indicate if changes were made. The images or other third party material in this article are included in the article's Creative Commons licence, unless indicated otherwise in a credit line to the material. If material is not included in the article's Creative Commons licence and your intended use is not permitted by statutory regulation or exceeds the permitted use, you will need to obtain permission directly from the copyright holder. To view a copy of this licence, visit http://creativecommons.org/licenses/by/4.0/. The Creative Commons Public Domain Dedication waiver (http://creativecommons.org/publicdomain/zero/1.0/) applies to the data made available in this article, unless otherwise stated in a credit line to the data. 


\section{Introduction}

The human gastrointestinal (GI) tract contains an estimated $3.8 \times 10^{13}$ bacteria $\left(10^{11} / \mathrm{mL}\right.$ contents $)$ that play an essential role in digestion, pathogen resistance and the development of different sensory systems within the GI tract including the immune system [1-3]. Gramnegative Bacteroides thetaiotaomicron (Bt) is a prominent member of the intestinal microbiota of many animals [4-6]. Bt has important functions in nutrient absorption and promoting barrier function via its effect on goblet cell development and mucus secretion [7, 8]. In addition, Bt has been described to be both protective and pathogenic in rodent models of intestinal inflammation [9-11]. Typical of all gram-negative bacteria, Bt generates nanosized outer membrane vesicles (OMVs) during its normal growth $[12,13]$. The content of OMVs is varied, including enzymes and hydrolases, cell-wall components such as lipooligosaccharide and peptidoglycan, nucleic acids and metabolites [14-16]. Importantly, OMVs are packaged within a lipid bilayer which protects them from physical, chemical and biological degradation within the GI tract $[17,18]$.

The production of OMVs by pathogenic gramnegative bacteria including Vibrio cholerae, Neisseria meningitidis, Helicobacter pylori and Haemophilus influenzae plays a central role in infection and the delivery of toxins to host cells, and stimulation of the immune system [13, 19-22]. OMVs produced by commensal bacterial species of the genus Bacteroides have been implicated in microbial and immune homeostasis. For example, polysaccharide A expressed on the surface of OMVs from Bacteroides fragilis can promote both regulatory $\mathrm{T}$ cell responses and production of interleukin (IL)-10 by dendritic cells (DC) in a TLR-2 and Gadd45 $\alpha$-dependent manner that contributes to protection in a mouse model of acute colitis [23]. Bt produces OMVs containing phosphatases and sulfatases which are implicated in epithelial intracellular signalling and immunomodulatory functions [24, 25]. In fact, OMVs from both pathogenic and commensal strains have been used in vaccine formulations, supporting their role in microbe-host immune system crosstalk [26-29].

Most of our understanding of OMVs-host interactions comes from animal model systems with the human immune response to $\mathrm{Bt}$ and OMVs being poorly characterised. Therefore, we have examined how DC from healthy individuals respond to Bt OMVs and how these responses change in individuals with inflammatory bowel disease (IBD). The IBDs, including Crohn's disease (CD) and ulcerative colitis (UC), are chronic, relapsing-remitting diseases of the GI tract affecting more than $0.3 \%$ of western populations [30]. Both CD and UC are characterised by destruction of the mucosal barrier leading to inappropriate responses to the microbiota. These altered responses stem from changes in the underlying immune system, including loss of key populations of regulatory innate and adaptive immune cells leading to overexuberant pathogenic $\mathrm{T}$ cell responses [31-36]. These changes are also associated with intestinal microbial dysbiosis characterised by reductions in Bacteroidetes and Firmicutes with concomitant increase in Proteobacteria [37].

IL-10 is an immunoregulatory cytokine and is essential for intestinal homeostasis as demonstrated in mice lacking either IL-10 or IL-10 receptor genes that spontaneously develop inflammatory disease $[38,39]$. IL-10 is important for regulating $\mathrm{T}$ cell responses to the commensal microbiota and largely acts via the innate immune system, including macrophages and DC [40-42]. In humans, the importance of the IL-10 pathway in regulating immune response is clear from patients with monogenic defects in IL1O and IL1OR genes that develop rapid onset IBD [43-45].

$\mathrm{DC}$ are key antigen-presenting cells that both produce and respond to IL-10 to regulate immune responses [42, 46], with both human studies and mouse models demonstrating their central role in immune homeostasis and microbial tolerance [47-50]. This, together with the alterations to DC subsets in IBD [32-34, 51, 52], led us to hypothesise that $\mathrm{DC}$ are key effectors in the healthy response to Bt that is mediated by OMVs and that DC responses to Bt-derived OMVs may be altered in IBD.

\section{Results}

Bt OMVs elicit production of immunoregulatory IL-10 by DCs of the healthy human colon

During normal anaerobic growth, Bt cells produce and release OMVs into the external milieu which consists of nanostructures exhibiting a typical spherical lipid bilayer (Fig. 1a) [53]. In order to examine mucosal immune responses to OMVs, colonic biopsies from healthy individuals (see Table 3) were cultured intact in a polarised in vitro culture system (pIVOC) for $6 \mathrm{~h}$ with $10^{8}-10^{9} \mathrm{Bt}$ OMVs/mlor medium alone added to the apical surface. Immune mediators were then measured in tissue lysates. Amongst the panel of 13 cytokines/chemokines tested (see the "Methods" section) all but IFN 22 were induced at detectable levels though TNF- $\alpha$, IL-17a, IL-12p70 and IL-23 were very low $(<5 \mathrm{pg} / \mathrm{ml})$ (Supplementary Figure 1a). Those cytokines significantly upregulated in response to OMVs were chemoattractant MCP-1 (CCL2) $(p<0.001)$, IFN- $\gamma(p<0.01)$, IL-8, IL-1 $\beta$, IL-6 and notably IL-10 (all $p<0.05$; Fig. 1b).

To determine if DC were a source of cytokines in the pIVOC system, total lamina propria (LP) cells were obtained from five distal and five proximal colonic biopsies by enzymatic digestion and were cultured for $20 \mathrm{~h}$ in the presence of either non-viable (freeze-killed) $\mathrm{Bt}\left(10^{7} \mathrm{cfu} / \mathrm{mL}\right), \mathrm{Bt}$ 

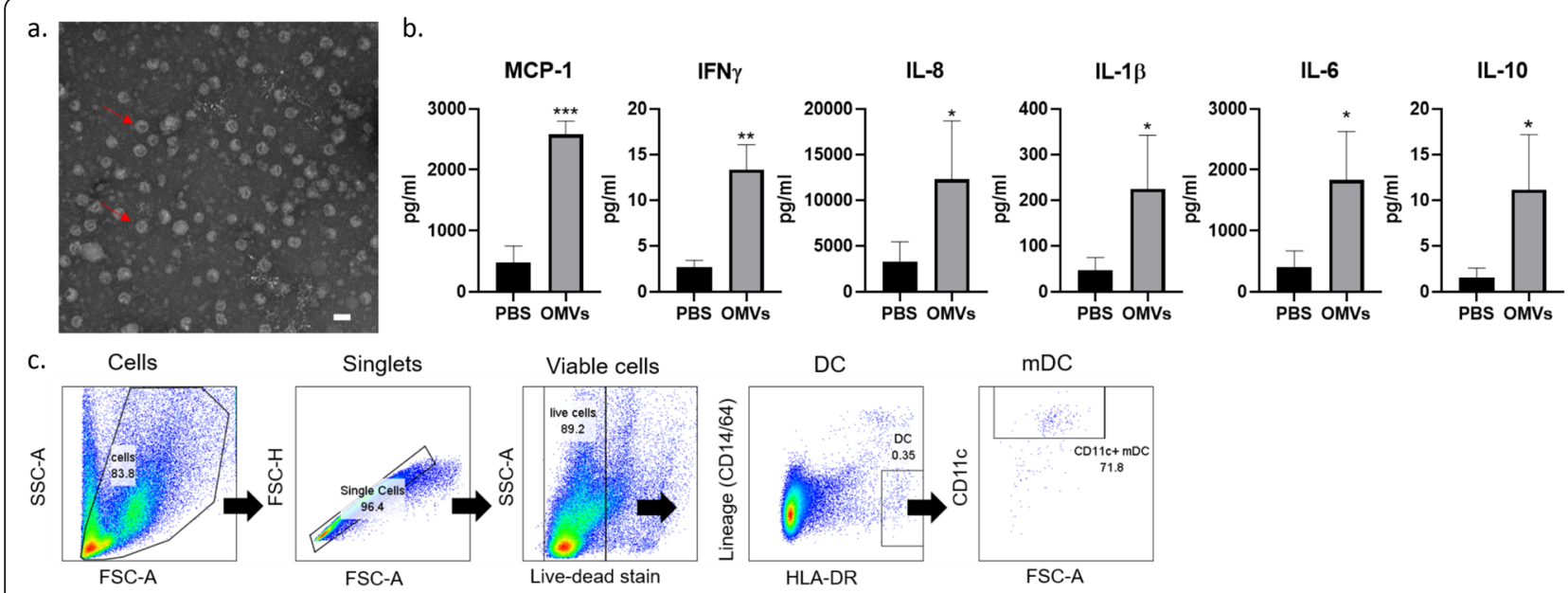

d.

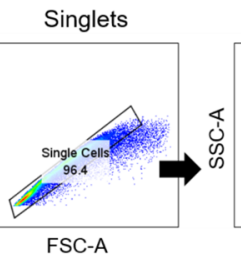

Viable cells

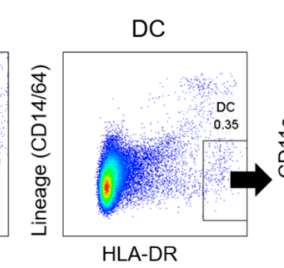

$\mathrm{mDC}$

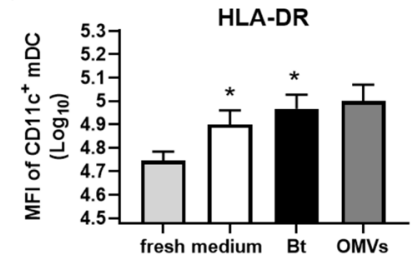

e.
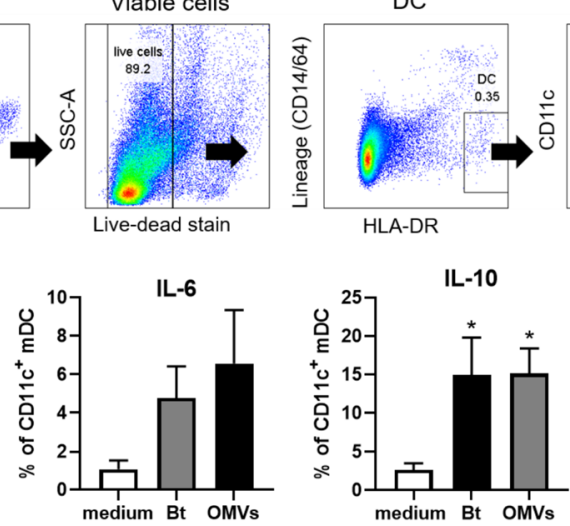

Fig. 1 Bt OMVs stimulate production of immunoregulatory IL-10 from whole colonic biopsies and colonic LP DC. During normal anaerobic growth, Bt cells produce and release OMVs into the external milieu. a Electron microscope photograph of OMVs collected by sterile filtration of Bt culture supernatants through $0.22 \mu \mathrm{m}$ membranes. Red arrows point to spherical nanostructures consisting of lipid bilayer. Scale bar, $~ 100 \mathrm{~nm}$. Colonic biopsies taken from the rectosigmoid junction of healthy individuals were grown in a pIVOC system mucosal side up within Snapwell inserts for $6 \mathrm{~h}$ in IVOC medium with or without $10^{8}-10^{9}$ Bt OMVs. b Following culture, biopsies were snap-frozen and cytokines and chemokines were measured within tissue lysates by LEGENDplex cytokine bead array. Amounts of MCP-1, IFN- $\gamma$, IL-8, IL-1 $\beta$, IL-6, and IL-10 shown are mean \pm SEM values from $n=4$ healthy controls with two experimental replicates each. Statistical significance was determined using nonparametric Mann-Whitney $U$ tests; ${ }^{*} p<0.05 ;{ }^{* *} p<0.01 ;{ }^{* * *} p<0.001$. Five biopsies each from proximal and distal colon of healthy individuals were washed with DTT/EDTA and digested with collagenase/liberase to obtain total LP cells. Cells were then cultured for $20 \mathrm{~h}$ in the presence of either killed $10^{7} \mathrm{Bt} / \mathrm{mL}$ or $10^{10} \mathrm{Bt} \mathrm{OMV} / \mathrm{mL}$ in complete RPMI medium, and $\mathrm{mDC}$ were examined by flow cytometry. $\mathbf{c}$ Identification of mDC within the total LP cells. d Mean fluorescence intensity of HLA-DR on total $\mathrm{mDC}$ in response to medium only, Bt or Bt OMVs. Statistical significance was determined by one-way ANOVA with Dunnett's multiple comparisons test; ${ }^{*} p<0.05$. e Proportion of mDC expressing IL-6 (top panel) and IL-10 (bottom panel) within the colonic LP. Pooled data from $n=6 \mathrm{HC}$. Statistical significance was determined using non-parametric Kruskal-Wallis ANOVA with Dunn's multiple comparisons test; ${ }^{*} p<0.05$

OMVs $\left(10^{10} / \mathrm{mL}\right)$ or medium only. DC was identified as HLA-DR ${ }^{+}$cells which did not express CD14 or CD64, markers of macrophages or monocytes (Fig. 1c). The majority (> 60\%) of DC expressed CD11c, a marker of myeloid $(\mathrm{m}) \mathrm{DC}$ and were activated by both Bt and its OMVs as shown by increased expression of HLA-DR (Fig. 1d). Further, while a proportion of LP mDC expressed IL-6 (5-10\%) in response to $\mathrm{Bt}$ and OMVs, a greater and significant $(p<$ $0.05)$ proportion of $\mathrm{mDC}$ expressed IL-10 in response to either Bt or Bt OMVs (10-30\%) compared to medium-only control cultures (Fig. 1e), consistent with DC being a source of IL-10 detected in intact colonic biopsies (Fig. 1b). Importantly, absolute numbers of $\mathrm{mDC}$ expressing IL-10, but not IL-6, were also significantly increased $(p<0.05)$ after culture with Bt or Bt OMVs compared to the medium-only condition (Supplementary Figure 1b). Thus, in health, IL10 is a predominant cytokine produced locally by DC in the colon in response to $\mathrm{Bt}$ and $\mathrm{Bt}$ OMVs.

\section{Bt and Bt OMVs promote protective circulating DC responses}

To determine whether $\mathrm{Bt}$ and $\mathrm{Bt}$ OMVs elicited a similar response from circulating DC, peripheral blood mononuclear cells (PBMC) from healthy donors were stimulated with $\mathrm{Bt}$ or varying doses of Bt OMVs for $20 \mathrm{~h}$ and $\mathrm{DC}$ responses were examined by multiparameter flow cytometry. DC were identified within PBMC based upon the absence of expression of lineage-specific markers (CD3/CD14/CD16/CD19/CD34) and being HLA-DR ${ }^{+}$. Within this population, both $\mathrm{CD} 11 \mathrm{c}^{+} \mathrm{mDC}$ and $\mathrm{CD} 123^{+}$ plasmacytoid (p)DC were identified with $\mathrm{mDC}$ predominating (Fig. 2a).

To examine how DC responded to culture with $\mathrm{Bt}$ and Bt OMVs, expression of the activation marker CD80 and intracellular cytokines IL- 6 and IL- 10 were measured by flow cytometry. Results are displayed as percentages of total $\mathrm{mDC}$ and $\mathrm{pDC}$ staining positively for these 


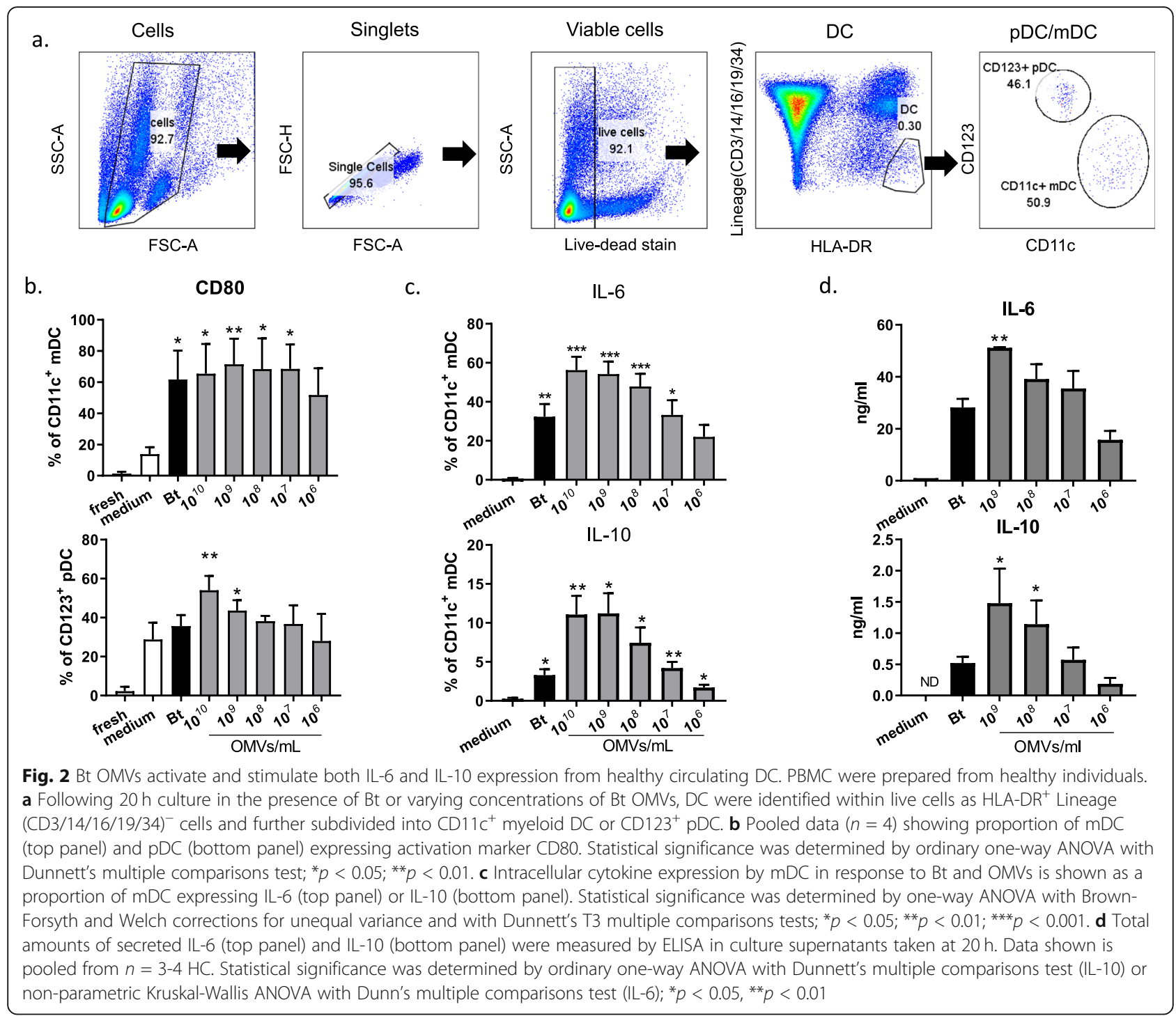

markers. Both Bt and Bt OMVs activated $\mathrm{mDC}$ and $\mathrm{pDC}$ as seen by expression of co-stimulatory marker CD80 on the majority of $\mathrm{mDC}(60-80 \%)$ and a major proportion of pDC (40-50\%) (Fig. 2b). However, cytokine responses were predominated by $\mathrm{mDC}$ with 30-60\% expressing IL-6 in response to Bt and to a range of concentrations of Bt OMVs (Fig. 2c) while only small proportion of pDC $(<10 \%)$ produced IL-6 in response to high concentrations of Bt OMVs (Supplementary Figure 2a and b). Importantly, IL-10 was expressed by a significant $(p<$ $0.01)$ proportion of $\mathrm{mDC}(10-15 \%)$ in response to both $\mathrm{Bt}$ and a range of Bt OMV concentrations but not by pDC (Fig. 2c and Supplementary Figure 2a and b). When levels of cytokines were measured in culture supernatants, there was compared to control cultures a significant $(p<0.01)$ amount of IL-6 in response to the highest concentration of Bt OMVs $\left(10^{9} / \mathrm{mL}\right)$, while IL10 was detected in response to $\mathrm{Bt}$ OMVs at concentrations of $\geq 10^{8} / \mathrm{mL}(p<0.05)$ (Fig. $\left.2 \mathrm{~d}\right)$. These findings suggest that, as seen with mucosal DC, circulating immune responses to Bt OMVs in healthy individuals involve a balance of protective IL- 6 and regulatory IL-10.

\section{Reduced IL-10 response to $\mathrm{Bt}$ OMVs and associated loss of $\mathrm{CD} 103^{+} \mathrm{DC}$ in IBD}

$\mathrm{CD}$ and UC are characterised by a loss of mucosal barrier integrity, leading to translocation of bacteria and triggering of inappropriate immune responses. Alterations in colonic DC populations, including loss of regulatory $\mathrm{CD}_{103}{ }^{+} \mathrm{DC}$, have been demonstrated in IBD [33, $34,49,50]$. We confirmed these findings in our patient cohort (see Table 1) by characterising $\mathrm{mDC}$ in LP cells from proximal and distal colon of healthy controls $(\mathrm{HC})$ and individuals with $\mathrm{CD}$ and $\mathrm{UC}$, including expression of CD103 and SIRPa (a myeloid marker) which 
Table 1 Clinical characteristics of St Mark's Hospital colonoscopy patients donating colonic biopsies

\begin{tabular}{|c|c|c|c|}
\hline Characteristic & Healthy control (HC) & Ulcerative colitis (UC) & Crohn's disease (CD) \\
\hline$n$ & 27 & 14 & 10 \\
\hline Male/female & $11 / 16$ & $7 / 7$ & $3 / 7$ \\
\hline Age at sampling & $51(20-77)$ & $47.3(24-70)$ & $47.2(21-77)$ \\
\hline \multicolumn{4}{|l|}{ Inflammation categories } \\
\hline None & & 4 & 4 \\
\hline Mayo 1 (mild disease) & & 5 & 3 \\
\hline Mayo 2 (moderate disease) & & 5 & 1 \\
\hline Mayo 3 (severe disease) & & 0 & 1 \\
\hline Perianal disease & & 0 & 0 \\
\hline Chronic obstruction & & 0 & 0 \\
\hline Terminal ileum resection & & 0 & 1 \\
\hline \multicolumn{4}{|l|}{ IBD medications at sampling } \\
\hline None & & 8 & 5 \\
\hline Aminosalicylates & & 5 & 3 \\
\hline Azathioprine/6-mercaptopurine & & 1 & 3 \\
\hline Buscopan & & 0 & 1 \\
\hline \multicolumn{4}{|l|}{ Non-IBD medications at sampling } \\
\hline Ondansetron & & 0 & 1 \\
\hline None & & 14 & 9 \\
\hline
\end{tabular}

Demographic and clinical data analysed in Figs. 1, 2, 3, 4 and 5 and Supplementary Figs 1-4

subdivides $\mathrm{mDC}$ into $\mathrm{SIRP \alpha}^{+} \mathrm{CD} 103^{-}$(similar to monocyte-derived DC), $\mathrm{SIRP \alpha}^{+} \mathrm{CD} 103^{+}$(similar to $\mathrm{CD} 1 \mathrm{c}^{+}$ cDC2) and $\mathrm{SIRP \alpha}^{-} \mathrm{CD}_{103}{ }^{+}$(similar to $\left.\mathrm{CD} 141^{+} \mathrm{CDC} 1\right) \mathrm{DC}$ [54-56]. Individuals with $\mathrm{UC}$ and $\mathrm{CD}$ were subdivided into active (red symbols) or inactive (black symbols) disease based on histological findings (Table 1) and blood or faecal markers of inflammation (Table 2). Inactive disease was defined as having macroscopically normal mucosa from rectum to terminal ileum (TI) from colonoscopy and/or not having inflammatory markers in blood and faeces at time of sampling. Absolute numbers of $\mathrm{mDC}$ were unchanged in IBD compared to $\mathrm{HC}$, regardless of disease activity (Supplementary Figure 3a). Total $\mathrm{CD}_{103^{+}} \mathrm{mDC}$ were also only significantly reduced $(p<0.05)$ in the proximal colon of CD patients (Supplementary Figure $3 \mathrm{~b}$ ) and specifically those with active disease trended towards significance $(p=0.0562)$ Further, when $\mathrm{CD}_{103^{+}} \mathrm{mDC}$ were subdivided based on expression of SIRP $\alpha$, both SIRP $\alpha^{+}$ $\mathrm{CD}_{103}{ }^{+}$and $\mathrm{SIRP \alpha}^{-} \mathrm{CD}_{103^{+}} \mathrm{DC}$ were significantly reduced $(p<0.05 ; p<0.05)$ in the proximal colon of all CD patients, along with $\mathrm{SIRP}^{-} \mathrm{CD} 103^{+} \mathrm{DC}$ being substantially reduced ( $p=0.0512)$ in the distal colon of all UC patients compared to HC (Supplementary Figure 3c, top and middle panels). However, when UC and CD patients were subdivided based on disease activity, only CD patients with active disease had substantial reductions $(p=0.0885)$ in $\mathrm{SIRP}^{+} \mathrm{CD} 103^{+} \mathrm{DC}$ and significant reductions $(p<$ $0.05)$ in $\mathrm{SIRP}^{-} \mathrm{CD}_{103^{+}} \mathrm{DC}$. The numbers of $\mathrm{SIRP \alpha}^{+}$
$\mathrm{CD}_{103^{-}} \mathrm{DC}$ in either the proximal or distal colon of UC and $\mathrm{CD}$ patients were not different to $\mathrm{HC}$ (Supplementary Figure 3c; bottom panels) and this held true when patients were subdivided based on disease activity. Thus, both CD and $\mathrm{UC}$ are characterised by loss of $\mathrm{CD} 103^{+} \mathrm{DC}$ in the colonic LP and in CD the loss of $\mathrm{CD}_{103^{+}} \mathrm{DC}$ occurred in individuals with active disease.

Having confirmed alterations in DC populations in IBD patients, we next investigated if the immune response to Bt OMVs was also altered in IBD patients. To this end, total LP cells from distal and proximal colon of UC patients (all with mild active (Mayo 1) disease as defined by histological findings (Table 1), and blood/faecal inflammatory markers (Table 2) were stimulated for $20 \mathrm{~h}$ with $10^{10} \mathrm{Bt} \mathrm{OMV} / \mathrm{mL}$ or medium only and intracellular cytokine expression by $\mathrm{DC}$ was examined. Unlike in $\mathrm{HC}$, Bt OMVs did not stimulate a significant proportion of $\mathrm{mDC}$ from LP of UC patients to express IL-6 or IL-10 (Fig. 3a). Likewise, despite similar numbers of total $\mathrm{mDC}$ in $\mathrm{UC}$ and $\mathrm{HC}$, absolute numbers of IL-6- or IL-10-expressing $\mathrm{mDC}$ were not increased by Bt OMVs in UC (Supplementary Figure $4 \mathrm{a}$ and b). There was a non-significant trend towards reduced proportions and absolute numbers of $\mathrm{mDC}$ expressing both IL-6 and IL-10 in UC compared to $\mathrm{HC}$ (Fig. $3 \mathrm{~b}$ and Supplementary Figure $4 c)$. Thus, these findings suggest a loss of immunoregulatory $\mathrm{DC}$ response to $\mathrm{Bt}$ OMVs in $\mathrm{UC}$ which 
Table 2 Clinical characteristics of St Mark's Hospital blood donors and healthy volunteers

\begin{tabular}{|c|c|c|c|}
\hline Characteristic & Healthy control $(\mathrm{HC})$ & Ulcerative colitis (UC) & Crohn's disease (CD) \\
\hline$n$ & 17 & 11 & 7 \\
\hline Male/female & $7 / 10$ & $4 / 7$ & $2 / 5$ \\
\hline Age at sampling & $44.3(17-86)$ & $46(26-65)$ & $58.6(23-80)$ \\
\hline \multicolumn{4}{|l|}{ Inflammation categories } \\
\hline $\operatorname{CRP}(>5)$ & & 3 & 1 \\
\hline $\mathrm{ESR}(>20)$ & & 1 & 0 \\
\hline Faecal calprotectin (> 55) & & 2 & 1 \\
\hline \multicolumn{4}{|l|}{ Symptoms at sampling } \\
\hline Diverticular disease & & 1 & 0 \\
\hline Diversion colitis & & 0 & 1 \\
\hline Fistulating Crohn's & & 0 & 1 \\
\hline \multicolumn{4}{|l|}{ IBD medications at sampling } \\
\hline None & & 9 & 5 \\
\hline Aminosalicylates & & 2 & 1 \\
\hline Azathioprine/6-mercaptopurine & & 0 & 0 \\
\hline Adalimumab & & 0 & 1 \\
\hline \multicolumn{4}{|l|}{ Non-IBD medications at sampling } \\
\hline Vitamins D/D3/ B12/B9 & & 1 & 1 \\
\hline Loperamide & & 0 & 1 \\
\hline Alendronate & & 0 & 1 \\
\hline Metformin & & 1 & 0 \\
\hline Tamoxifen & & 1 & 0 \\
\hline Simvastatin & & 1 & 0 \\
\hline None & & 10 & 6 \\
\hline
\end{tabular}

Demographic and clinical data analysed in Figs. 1, 2, 3, 4 and 5 and Supplementary Fig 1-4

may in part be explained by the reduction in immunoregulatory $\mathrm{CD}_{103}{ }^{+} \mathrm{DC}$ in these patients (Supplementary Figure 3).

\section{Circulating DC IL-10 response to Bt OMVs is also reduced in both UC and CD}

To assess whether changes in colonic DC and response to Bt OMVs in IBD were reflected systemically in individuals with $\mathrm{CD}$ or $\mathrm{UC}, \mathrm{PBMC}$ were used to examine circulating DC responses. In these experiments, disease activity was determined for UC and CD patients using both macroscopic histological findings from colonoscopy (Table 1) and blood or faecal markers of inflammation (Table 2). Inactive disease was defined as having macroscopically normal mucosa from rectum to terminal ileum (TI) from colonoscopy and/or not having inflammatory markers in blood and faeces at time of sampling.

As in Fig. 2a, $\mathrm{mDC}$ were identified in $\mathrm{PBMC}$ as CD11c ${ }^{+}$HLA-DR $^{+}$lineage marker (CD3/14/16/19/34) negative cells. To examine how $\mathrm{mDC}$ responded to culture with $\mathrm{Bt}$ and $\mathrm{Bt}$ OMVs, expression of intracellular cytokines IL-6 and IL-10 were measured by flow cytometry.
Results are displayed as percentages of total $\mathrm{mDC}$ staining positively for these markers. Following $20 \mathrm{~h}$ culture, a significant proportion of $\mathrm{mDC}$ expressed IL-6 in response to both $\mathrm{Bt}$ and high doses of Bt OMVs in both inactive UC $\left(\geq 10^{9} \mathrm{OMVs} / \mathrm{mL}\right)$ or inactive $\mathrm{CD}\left(\geq 10^{9} \mathrm{OMVs} / \mathrm{mL}\right)$ patients, which was comparable to the response of $\mathrm{mDC}$ from $\mathrm{HC}$ (Fig. 4a). However, neither Bt nor OMVs induced significant expression of IL-10 by $\mathrm{mDC}$ in inactive $\mathrm{UC}$ patients and the proportion of $\mathrm{mDC}$ that expressed IL-10 was significantly lower $(p<0.001 ; p<0.05)$ than that of $\mathrm{HC}$ at high doses of OMVs $\left(\geq 10^{9} \mathrm{OMVs} / \mathrm{mL}\right)$ (Fig. 4b). In patients with inactive CD, a low but significant $(p<0.05)$ proportion of $\mathrm{mDC}(10 \%)$ expressed IL-10 in response to the highest dose of OMVs $\left(10^{10} / \mathrm{mL}\right)$ but at $10^{9} / \mathrm{mL}$ Bt OMVs the proportion of $\mathrm{mDC}$ expressing IL10 was significantly $(p<0.01)$ reduced compared to $\mathrm{HC}$ (Fig. 4c). Interestingly, when $\mathrm{DC}$ responses to $\mathrm{Bt}$ and $\mathrm{Bt}$ OMVs were examined in UC patients with active disease, the proportion of IL-10 expressing $\mathrm{mDC}$ was comparable to that of healthy controls (Fig. 4d), suggesting intrinsic alterations in the immune system rather than inflammation drives the loss of regulatory response to Bt OMV in UC. 
a.

UC IL-6

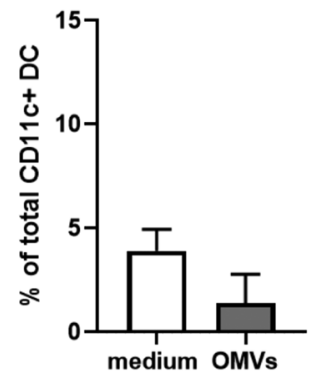

Medium only

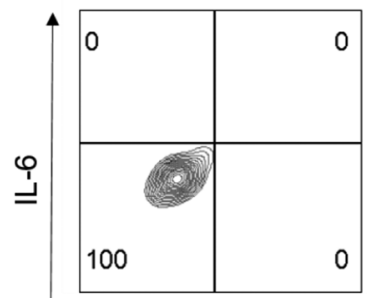

UC IL-10

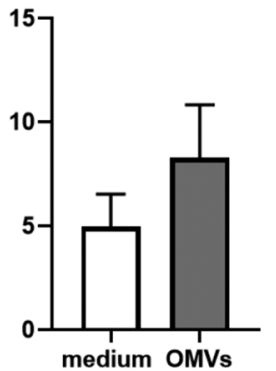

Bt OMVs $10^{10}$

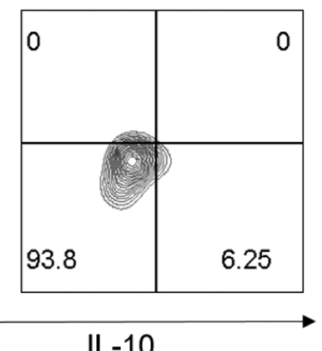

b.
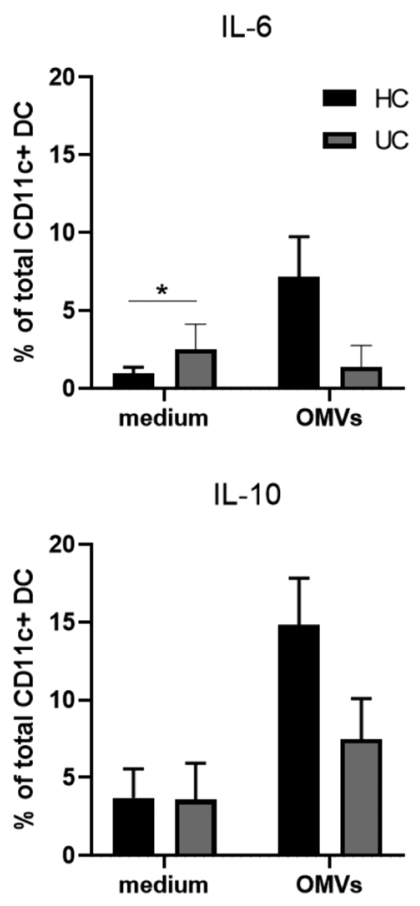

Fig. 3 Lack of IL-10 response from colonic DC to Bt OMVs in ulcerative colitis. Following $20 \mathrm{~h}$ culture of LP cells from five proximal and five distal colon biopsies from UC patients with Bt OMVs $10^{10} / \mathrm{mL}$ or medium only, DC cytokine responses were examined by FACS. a Pooled data $(n=3)$ showing proportions of $\mathrm{mDC}$ expressing IL-6 (top left) and IL-10 (top right) and representative FACS plots from one UC patient (bottom). $\mathbf{b}$ Comparison of proportions of mDC expressing IL-6 (top) and IL-10 (bottom) in UC $(n=3)$ to HC $(n=6)$. Statistical significance was determined using unpaired $t$ tests; ${ }^{*} p<0.05$

\section{Specificity of DC cytokine response to commensal bacteria}

To determine if altered responses existed to bacteria other than Bt in individuals with UC, circulating DC responses to a selection of 19 additional human intestinal commensal bacteria were examined, including several gram-negative species. As in previous experiments, disease activity was determined for UC patients using both macroscopic histological findings from colonoscopy (Table 1) and blood or faecal markers of inflammation (Table 2). Inactive disease was defined as having macroscopically normal mucosa from rectum to TI from colonoscopy and/or not having inflammatory markers in blood and faeces at time of sampling. For UC patients with inactive disease, the proportion of $\mathrm{mDC}$ expressing IL-10 in PBMC in response to each of the 19 bacteria tested was comparable to $\mathrm{HC}$ (Fig. 5a).

We additionally examined circulating DC responses to a gram-negative commensal of the human respiratory tract, Prevotella nanceiensis (Pn), and its OMVs [57]. Pn, closely related to $\mathrm{Bt}$, exhibits weak inflammatory properties indicating that it is tolerated by the respiratory immune system $[57,58]$. In response to non-viable (freeze-killed) Pn, a proportion of $\mathrm{mDC}$ derived from PBMC of healthy donors expressed both IL-6 (40-50 \%) and IL-10 (10\%) (Fig. 5b). However, in contrast to the response to $\mathrm{Bt}$ OMVs (Fig. 2b), the majority ( $\geq 80 \%$ ) of $\mathrm{mDC}$ did not express either IL-6 or IL-10 in response to Pn OMVs even at the highest dose of $10^{9} \mathrm{OMV} / \mathrm{mL}$ (Fig. 5b).

Further, in inactive UC patients, the proportion of $\mathrm{mDC}$ expressing IL-6 or IL-10 in response to Pn OMVs was comparable to $\mathrm{HC}$ with only IL-10 being reduced in response to $\mathrm{Pn}$ (Fig. 5c). This suggests that the circulating DC IL-10 response elicited by Bt OMVs in HC may be restricted to specific members of the microbiota, with the reduced IL-10 response in inactive UC also potentially being specific to Bt OMVs.

\section{Discussion}

Despite Bt being extensively used as a model organism to study host immune-microbiota interactions [59], the nature of the immune response to $\mathrm{Bt}$ in humans is poorly characterised. Here, we present novel data showing that the response of intestinal mucosal cells to Bt involves a balance in the production of protective IL-6 and regulatory IL-10 to which DC both locally and systemically contribute. Furthermore, this balanced response is mediated by OMVs, nanosized vesicles produced by the 


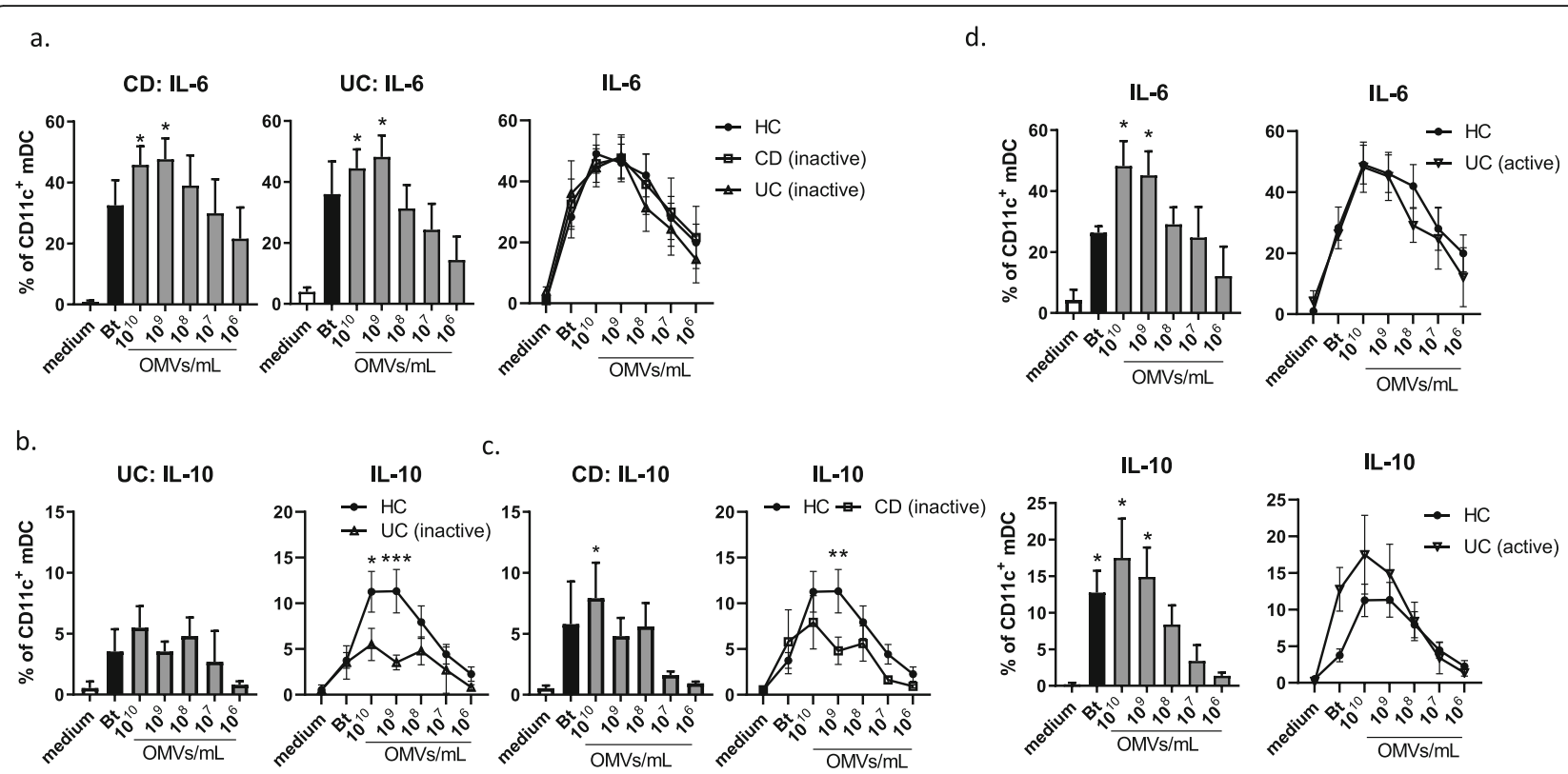

Fig. 4 Loss of immunoregulatory IL-10 response by circulating DC to Bt OMVs in CD and UC. Whole PBMC were separated from blood of individuals with inactive Crohn's Disease (CD) or inactive or active ulcerative colitis (UC) and intracellular cytokine analysis of mDC was examined by FACS. a Pooled data from inactive UC $(n=5)$ and CD $(n=5)$ patients show proportions of $\mathrm{mDC}$ expressing $(\mathbf{a}) \mathrm{IL}-6$ in response to Bt and Bt OMVs and compared to HC. $\mathbf{b}$ Pooled data from inactive UC $(n=5)$ show proportions of mDC expressing IL-10 in response to Bt and Bt OMVs and compared to HC. c Pooled data from inactive CD $(n=5)$ show proportions of mDC expressing IL-10 in response to Bt and Bt OMVs and compared to HC. Statistical significance was determined by Brown-Forsythe and Welch ANOVA for unequal variance with Dunnett's T3 multiple comparisons test or two-way ANOVA with Holm Sidak's multiple comparisons test; ${ }^{*} p<0.05,{ }^{* *} p<0.01,{ }^{* * *} p<0.001$. d Pooled data from active UC $(n=3)$ showing proportions of mDC expressing IL-6 (top) or IL-10 (bottom) and comparison to HC. Statistical significance was determined by non-parametric Kruskal-Wallis ANOVA with Dunn's multiple comparison test; ${ }^{*} p<0.05$

bacteria which are known to cross the mucus layer of the intestine to directly interact with immune cells beneath the boundary epithelium [60]. Furthermore, we show that in individuals with $\mathrm{CD}$ and $\mathrm{UC}$ there is a loss of regulatory IL-10 response to Bt OMVs by bloodderived DC, while protective IL-6 responses are retained. In UC, there is also a lack of colonic DC IL-10 response to Bt OMVs and this accompanies a pronounced loss of immunoregulatory $\mathrm{CD}_{103^{+}} \mathrm{DC}$ in the colonic LP. Importantly, the altered circulating $\mathrm{DC}$ response to $\mathrm{Bt}$ OMVs is only seen in UC and CD patients with inactive disease, which suggests that underlying defects in the immune system rather than inflammation drive these responses. IL- 6 was significantly induced by Bt OMVs in healthy individuals both in whole colonic biopsy cultures as well as in blood DC. IL-6 is a pleiotropic cytokine produced by innate immune cells like DC in response to TLR stimulation. It has essential roles in driving B cell differentiation and antibody production as well as maintaining balanced $\mathrm{CD} 4^{+} \mathrm{T}$ helper responses by promoting Th17/Tfh cells and inhibiting regulatory $\mathrm{T}$ cells [61]. However, aberrant IL- 6 responses are implicated in the pathogenesis of inflammatory diseases including Crohn's disease and ulcerative colitis and blockade of IL-6 is protective in murine colitis [62-64]. Therefore, it is not surprising that we found an intact IL-6 response to $\mathrm{Bt}$ OMVs in $\mathrm{CD}$ and $\mathrm{UC}$ comparable to $\mathrm{HC}$ specifically in the periphery. However, in $\mathrm{HC}$ this was critically balanced by a significant IL-10 response which is known to directly inhibit IL-6-mediated responses [65-67]. In fact, we have shown that both $\mathrm{CD}$ and $\mathrm{UC}$ are characterised by heightened memory $\mathrm{B}$ cell and antibody responses to the commensal microbiota and a lack of IL-10-mediated suppression of IL-6 may directly contribute to this skewed B cell response [36]. Further, in colonic LP of UC patients, there was a clear lack of IL- 6 and IL-10 production by $\mathrm{DC}$ to $\mathrm{Bt}$ OMVs suggesting a nonresponsive phenotype which may contribute to a loss of colonic resident memory $\mathrm{T}$ cells in these patients [35, 36]. Thus, a deficient mucosal DC response to Bt OMVs, possibly due to loss of key populations of $\mathrm{CD}_{103^{+}} \mathrm{DC}$ and resident memory $\mathrm{T}$ cells, could lead to poorly regulated systemic responses and pathology.

The marked DC IL-10 response to Bt OMV may be specific as we did not see this response to OMVs generated by the closely related human lung commensal Pn despite a comparable IL-10 response to the whole bacterium. This may be related to regional, tissue and mucosa specific differences in addition to differences in OMV cargo and specific antigens able to elicit the IL-10 


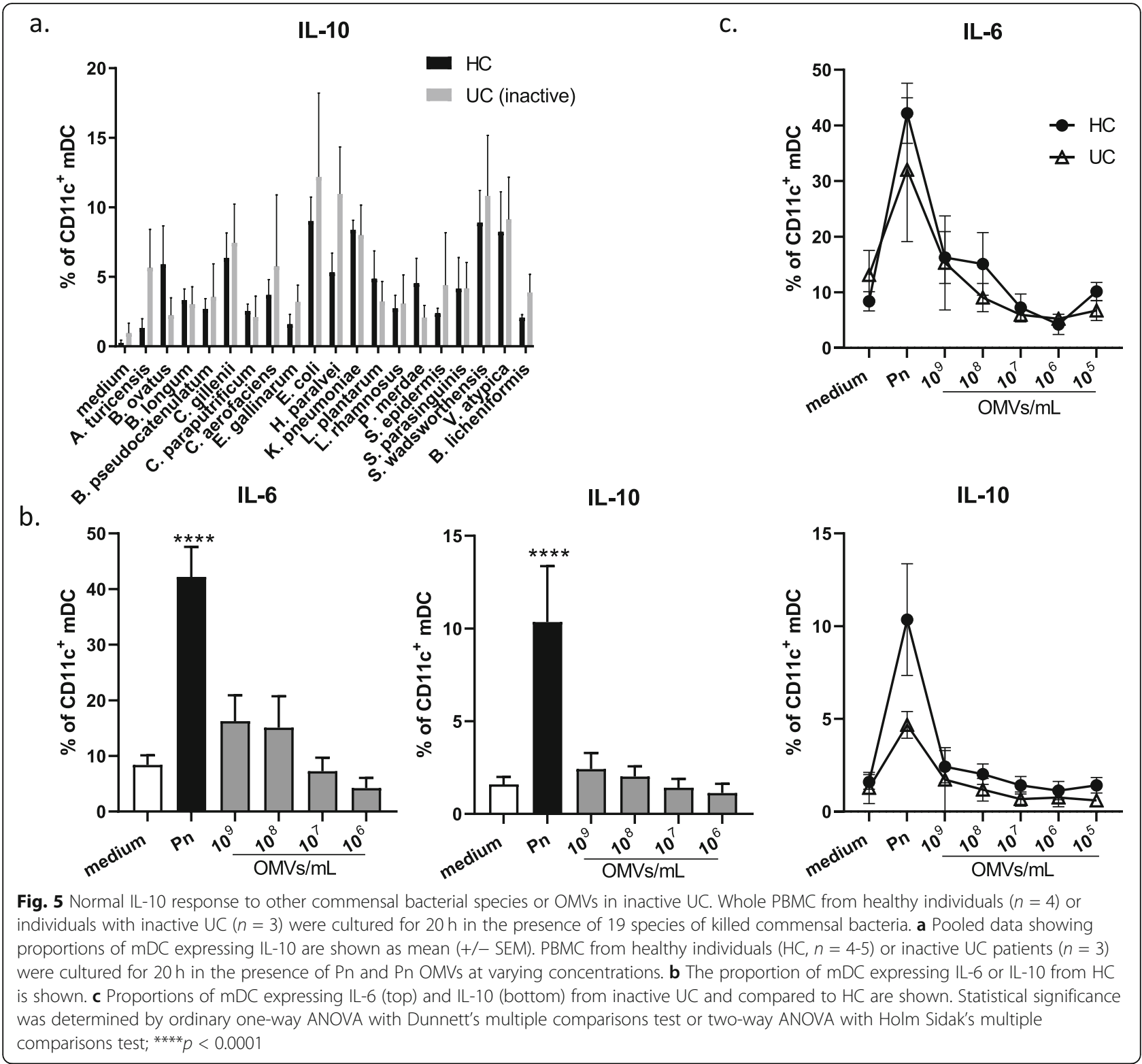

response by DC that are restricted to or are only accessible in Bt OMVs. An example of such species-specific expression of immunomodulatory molecules is the capsular polysaccharide A (PSA) antigen expressed by the closely related commensal species Bacteroides fragilis (Bf). The PSA antigen is expressed in Bf OMVs and elicits IL-10 production from DC in a TLR-2-dependent manner [23]. The immunomodulatory effect of Bt may also not be restricted to immune cells and DC. In the immortalised human colonic epithelial cell line Caco-2, Bt stimulates nuclear export of the NFkB subunit RelA in a mechanism involving PPAR $\gamma$, which in turn dampens inflammatory responses [9]. PPAR $\gamma$-mediated anti-inflammatory functions are well recognized, and agonists are being explored in the treatment of UC [68]. Bt has also been shown to contain a pyrin-like protein (PLP) which in Caco-2 cells dampens the NFkB pathways [11]. Although neither PLP nor stimulation of PPAR has been linked to Bt OMVs directly, it is compatible with its potential immunomodulatory properties. The NFkB pathways are directly involved in transcriptional regulation of both IL- 6 and IL-10 downstream of TLR stimulation $[62,67]$ and Bt OMVs may act via these pathways to control expression of these cytokines from DC. Future work to characterise the contents of the OMVs will be necessary to determine mechanisms of action on DC in health or IBD.

The importance of regulatory IL-10 to the healthy response of DC to Bt OMVs is congruent with observations in mice showing that $\mathrm{Bt}$ is colitogenic in $d n K O$ 
mice lacking IL-10 and TGF $\beta$-signalling pathways [10, 24]. Conversely, a strain of Bt different to that used in our study was shown to protect otherwise susceptible IL-10R-deficient mice or dextran sodium sulfate-treated mice and rats from developing colitis [11]. These discrepancies support the proposal that Bt protective functions are, at least in mice, not limited to IL-10-related pathways and may be dependent on environmental, bacterial strain- and host-specific factors [69]. Likewise in humans, Bt OMVs could elicit immunomodulatory functions via different mechanisms in addition to their role in directing balanced DC responses that could change in inflammatory settings such as in IBD. A recent study has demonstrated a key role for IL-10R signalling in DC in controlling aberrant Th1 responses both via inhibition of IL- $1 \beta$ and IL-12 in paediatric IBD and in an individual with IL10RA gene deficiency [70]. This fits with previous reports that IL-10 is both produced by and acts via DC to regulate intestinal inflammation [42]. In active UC, there was no loss of IL-10 expression by circulating $\mathrm{mDC}$ in response to Bt OMVs; however, it would have been of interest to additionally determine if IL-10 was able to inhibit downstream Th1 or Th17 type responses, characteristic of IBD [71, 72]. Especially given the essential role, IL-6 plays in driving inflammatory $\mathrm{T}$ cell responses and antibody production, Bt OMV-mediated induction of regulatory IL-10 may not be effective at dampening these responses in the context of inflammation. Likewise, it is possible that the normal IL-10 response in active UC is a result of DC or other cell types such as T or B cells having lower IL-10R expression or impaired pathway function leading to a positive feedback loop to produce more IL-10.

Unlike whole bacteria, OMVs can cross from the lumen of the intestine through the epithelial barrier and access organs and tissues beyond the GI tract [17, 60]. Exploiting this property of OMV, Bt has been successfully engineered to generate OMVs containing both therapeutic proteins and vaccine antigens for treating mucosal inflammation and generating protective mucosal and systemic immunity [28, 29]. Thus, Bt OMVs have considerable therapeutic potential. The fact that circulating DC responses to Bt and their OMVs largely reflect the local colonic DC response in health and in disease is interesting on several levels. Firstly, if intestinal disease activity can be assessed using a readout from the blood, this avoids the necessity for taking additional biopsies during colonoscopy. Secondly, the reduced IL-10 response to Bt OMVs in inactive $\mathrm{UC}$ was unique and could not be recapitulated in response to another related gram-negative commensal, Pn. Thus, Bt OMVs might be of use in highlighting an immune signature specific to UC that is detectable in blood samples. Finally, active inflammation appears to mask the underlying defects in
DC interplay with Bt OMVs, leading to a healthassociated circulating DC response. However, we did not fully explore all possible cytokines or pathways elicited by Bt OMVs and it is possible that in active IBD the signature may be distinct and different from health. For instance, Bt has been shown to elicit IL-8 from paediatric $\mathrm{CD}$ biopsies but not from healthy controls [73]. Additionally, reduced IL10RA expression and reduced responsiveness occur in a subgroup of more severe paediatric IBD patients and these are associated with enhanced IL-1 $\beta$ expression [70]. It will in future studies be important to identify the specific factor or factors present in Bt OMVs that trigger a healthy immune response to realise their potential use as a novel therapy for IBD.

\section{Conclusions}

Homeostatic and regulatory immune responses are generated to commensal bacteria both locally and systemically. For Bt, these responses involve a balance of host protective IL- 6 and regulatory IL-10 produced by DC. Importantly, OMVs produced by Bt are instrumental in eliciting this appropriate response both in the colonic mucosa and in the blood. In patients with $\mathrm{UC}$ and $\mathrm{CD}$, there is a loss of regulatory IL-10 response by DC to $\mathrm{Bt}$ OMVs which may contribute to the inflammatory milieu of the intestine and systemically in these diseases.

\section{Methods}

\section{Study design and sampling}

The aim of this study was to characterise the human DC response to Bt OMVs and determine whether it is altered in IBD. Healthy donors (age 17-86) undergoing investigative colonoscopy and individuals diagnosed with CD (age 21-80) and UC (age 24-70) were recruited from outpatient clinics at St Marks Hospital, London North West University Healthcare NHS Trust. Clinical characteristics of patients and controls are in Tables 1 and 2 . Active disease for $\mathrm{CD}$ and $\mathrm{UC}$ was defined as having macroscopic inflammation (rated from mild (1) to severe (3); see Table 1) from colonoscopy findings and/or presence of blood inflammatory markers C-reactive protein $(\mathrm{CRP})>5$ and erythrocyte sedimentation rate (ESR) between 1 and 20 or faecal calprotectin > 55 (See Table 2). Inactive disease was defined as no inflammation from rectum to terminal ileum (TI) according to colonoscopy findings and/or no more than one marker of inflammation in blood (CRP $>5$ or ESR between 1 and 20) and normal faecal calprotectin $(<55)$.

Patients were recruited over a fixed period determined by ethical permission, and no data were excluded at the end of the study. Additional healthy blood volunteers were recruited from hospital staff and visitors. Ethics approval was obtained from the Health Research Authority 
UK and London Brent Research Ethics Committee. Written informed consent was received from participants prior to inclusion in the study.

For whole biopsy culture experiments, healthy donors were recruited from endoscopy clinics at Norfolk and Norwich University Hospital following informed consent (see Table 3 for demographics data). Ethics approval was obtained from the University of East Anglia Faculty of Medicine and Heath Sciences Ethics Committee and Human Tissue Act Subcommittee ref 20152016-39HT and the Norfolk and Norwich University Hospital Research and Development Committee ref 20-01-16.

\section{Preparation of bacteria stocks}

Bacteroides thetaiotaomicron VPI-5482 (Bt) (DSMZ 2079) and Prevotella nanciensis (Pn) (DSMZ 19126) (both from DSMZ-German Collection of Microorganisms and Cell Cultures $\mathrm{GmbH}$, Braunschweig, Germany) were grown under anaerobic conditions at $37^{\circ} \mathrm{C}$ in brain heart infusion (BHI) medium (Oxoid/ Thermo Fisher, Basingstoke, UK) supplemented with $0.5 \mathrm{mg} / \mathrm{L}$ haemin (Sigma-Aldrich, St Louis, MO, USA) (BHI-haemin). Aliquots (1 mL) were centrifuged (13, $000 \mathrm{rpm}$ for $10 \mathrm{~min}$ ), supernatants removed and cell pellets were killed by snap-freezing before storage at $-80^{\circ} \mathrm{C}$. Pellets were resuspended in phosphatebuffered saline (PBS) for use. Other commensal bacteria were isolated from the caecum of healthy donors with the exception of Collinsella aerofaciens, which was from faeces [74-76]. Strains were grown anaerobically in Hungate tubes containing WilkinsChalgren broth at $37^{\circ} \mathrm{C}$ for $24 \mathrm{~h}$. Cell pellets were killed by snap-freezing at $-80{ }^{\circ} \mathrm{C}$ and enumerated by flow cytometry following SYBR Green staining.

\section{Preparation of bacterial OMVs}

The isolation of bacterial vesicles was done as previously described [25]. Briefly, Bt or Pn were grown under anaerobic conditions at $37^{\circ} \mathrm{C}$ in an anaerobic cabinet. Bacterial starter cultures were grown overnight in $20 \mathrm{~mL}$ BHI medium supplemented with $15 \mu \mathrm{M}$ haemin (Sigma-Aldrich) (BHIH). An aliquot $(0.5 \mathrm{~mL})$ of the starter culture was used to inoculate $500 \mathrm{~mL}$ BHI supplemented with $0.75 \mu \mathrm{M}$ haemin.

Table 3 Clinical characteristics of Norfolk and Norwich University Hospital colonoscopy patients donating colonic biopsies

\begin{tabular}{ll}
\hline Characteristic & Healthy control $(\mathrm{HC})$ \\
\hline$n$ & 4 \\
Male/female & $3 / 1$ \\
Age at sampling & $48.5(39-66)$ \\
\hline
\end{tabular}

Demographic and clinical data analysed in Fig. 1b and Supplementary Fig 1a
Cells were harvested after $16 \mathrm{~h}$ at an approximate OD $(600 \mathrm{~nm})$ of 4.0 . The cells were centrifuged at $5500 \times g$ for $45 \mathrm{~min}$ at $4{ }^{\circ} \mathrm{C}$ and the supernatants filtered through polyethersulfone (PES) membranes $(0.22 \mu \mathrm{m}$ pore size) (sartorius) to remove debris and cells. Supernatants were concentrated by ultrafiltration (100 kDa molecular weight cutoff, Vivaspin 50R, sartorius), the retentate was rinsed once with $500 \mathrm{~mL}$ of PBS (pH 7.4) and concentrated to $0.5 \mathrm{~mL}$.

Further purification was performed by fractionation of the OMV suspension by size-exclusion chromatography using a CL2-B sepharose (Sigma-Aldrich) column (120 $\mathrm{cm} \times 1 \mathrm{~cm})$ in PBS. The absorbance of the fractions was measured at $280 \mathrm{~nm}$ and the first fractions displaying an absorbance peak were pooled and concentrated down to $1 \mathrm{~mL}$ with a Vivaspin 20 centrifugal concentrator (100 $\mathrm{kDa}$ molecular weight cutoff, sartorius) and filtered through a $0.22 \mu \mathrm{m}$ PES membrane (sartorius). Concentration of vesicles was determined using nanoparticle tracking analysis as described previously [29]. Bt OMVs were at $10^{11}$ vesicles $/ \mathrm{mL}$ of $\mathrm{PBS}$ and $\mathrm{Pn}$ OMVs were at $2 \times 10^{10}$ vesicles $/ \mathrm{mL}$ of PBS.

\section{Transmission electron microscopy}

Bt OMVs were observed using negative staining with transmission electron microscopy (TEM) as previously described [53]. Briefly, isolated Bt OMVs were adsorbed to carbon-formvar-coated copper EM grids (Agar Scientific) for $1 \mathrm{~min}$ before wicking off with filter paper and negatively staining with $2 \%$ uranyl acetate solution $(\mathrm{BDH})$ in water for $1 \mathrm{~min}$. Grids were air-dried before analysis using a Tecnai G2 20 Twin TEM (FEI) at $\times 29$, 000 magnification.

\section{Polarised in vitro organ culture of colonic biopsies}

Colonic biopsies were taken from the rectosigmoid junction (around $18 \mathrm{~cm}$ from rectum) of macroscopically normal patients following informed consent. The polarised in vitro culture (pIVOC) of colonic biopsies used was adapted from a previous study [77]. Briefly, five colonic biopsies were collected in IVOC medium (Dulbecco's Modified Eagle's Medium (Sigma-Aldrich) (45 \%) and distilled water (45\%) containing $0.47 \mathrm{~g}$ NCTC-135 (Sigma-Aldrich), $0.11 \mathrm{~g}$ sodium bicarbonate (Sigma-Aldrich) and $10 \%$ newborn calf serum (NCS, Sigma-Aldrich). Each biopsy was orientated with the mucosal side uppermost on a cellulose nitrate filter within a Snapwell support and mounted within a well of a six-well plate containing $3 \mathrm{~mL}$ of IVOC medium. Once mounted, $200 \mu \mathrm{L}$ of IVOC medium was added apically with or without $10^{8}-10^{9}$ Bt OMVs $/ \mathrm{ml}$. The plate was incubated on a rotor $(12$ $\mathrm{rpm})$ at $37^{\circ} \mathrm{C}$ for $6 \mathrm{~h}$, after which the biopsy was removed intact from each support, flash-frozen in liquid 
nitrogen and stored at $-80{ }^{\circ} \mathrm{C}$ for later protein extraction and cytokine analysis.

\section{Biopsy tissue lysate extraction}

Biopsies were thawed on ice and a mixture of $122 \mu \mathrm{l}$ CellLytic MT (Sigma C3228), and $3 \mu$ protease inhibitor cocktail (Sigma P2714-1BTL) was added with 5 acidwashed glass beads ( $3 \mathrm{~mm}$ diameter). Homogenisation was performed using a MP Biomedical Fastprep-24 instrument (Fisher Scientific) at $4 \mathrm{~m} / \mathrm{s}$ for $30 \mathrm{~s}$. Samples were centrifuged at $10,000 \mathrm{rpm}$ at $4{ }^{\circ} \mathrm{C}$ for $2 \mathrm{~min}$. The tissue lysate was then transferred to a $1.5 \mathrm{ml}$ pre-cooled tube and centrifuged at $10,000 \mathrm{rpm}$ for $10 \mathrm{~min}$ at $4{ }^{\circ} \mathrm{C}$. The supernatant was carefully removed and stored at $-80{ }^{\circ} \mathrm{C}$ until use for cytokine bead array (see below).

\section{Isolation of colonic lamina propria cells}

Five proximal and five distal colon biopsies $(10 \mathrm{mg}$ tissue each) were obtained from macroscopically nonlesional tissue sites at routine colonoscopy in all patients as previously described [55]. Biopsies were washed in HBSS containing $1 \mathrm{mM}$ DTT and $1 \mathrm{mM}$ EDTA in a shaking incubator at $37^{\circ} \mathrm{C}$ for $30 \mathrm{~min}$ to remove the epithelial layer. Supernatants were discarded and wash was repeated for a second $30 \mathrm{~min}$ with HBSS/DTT/EDTA. Following discard of supernatants, biopsies were further digested in RPMI medium containing collagenase $\mathrm{D}(1 \mathrm{mg} / \mathrm{mL})$ and Liberase $\mathrm{TL}$ $(0.1 \mathrm{mg} / \mathrm{mL})$ for $1 \mathrm{~h}$ shaking at $37^{\circ} \mathrm{C}$ to release the lamina propria (LP) cells. LP cells were then filtered through a $100 \mu \mathrm{M}$ strainer, washed with PBS and centrifuged at $600 \mathrm{~g}$ for $5 \mathrm{~min}$ before proceeding to either culture or FACS staining.

\section{Isolation of peripheral blood mononuclear cells}

Blood obtained by venepuncture was diluted 1:1 (vol: vol) in PBS and layered over Ficoll-Paque Plus (Amersham Biosciences, Chalfont St. Giles, UK). After centrifugation at $800 \mathrm{~g}$ for $30 \mathrm{~min}$ at $18{ }^{\circ} \mathrm{C}$, PBMC were collected at the interface. PBMC were resuspended in complete medium (Dutch modified RPMI 1640 (Sigma-Aldrich, Dorset, UK) containing $100 \mathrm{U} /$ $\mathrm{mL}$ penicillin/streptomycin, $2 \mathrm{mM}$ L-glutamine, $50 \mu \mathrm{g} /$ $\mathrm{mL}$ gentamicin (Sigma-Aldrich) and 10\% faetal calf serum (TCS cell works, Buckingham, UK)) for culture or in PBS for FACS analysis.

\section{Bacterial stimulation of blood DC or LP cells}

Per condition, $5 \times 10^{5}$ PBMC were plated in 96-well U-bottom plates. PBMC were incubated with either $10^{6} / \mathrm{mL}$ freeze-killed commensal bacteria or OMVs at tenfold incremental concentrations from $10^{10}$ to 10 OMVs $/ \mathrm{mL}$ at $37{ }^{\circ} \mathrm{C}, 5 \% \mathrm{CO}_{2}$ for $20 \mathrm{~h}$. LP cells were isolated as described above and resuspended in complete medium as described for PBMC. LP cells (1-2 $\times 10^{5}$ per condition) were plated in 96-well Ubottomed plates. LP cells were incubated with either $10^{7} / \mathrm{mL}$ freeze-killed $\mathrm{Bt}, 10^{10} / \mathrm{mL}$ of Bt OMVs or complete medium only at $37^{\circ} \mathrm{C}, 5 \% \mathrm{CO}_{2}$ for $20 \mathrm{~h}$. For intracellular cytokine responses, $2 \mu \mathrm{M}$ monensin (Biolegend) was added to wells during incubation.

\section{Surface marker and intracellular cytokine profiling of DC}

Following incubation, PBMC and LP cells were washed with PBS and viability was determined by labelling cells with LIVE/DEAD ${ }^{\text {tu }}$ Fixable Near-IR Dead Cell Stain Kit (Thermo Fisher Scientific) according to the manufacturer's instructions. Cells were washed with FACS Buffer (1x PBS containing 2\% FCS, $1 \mathrm{mM}$ ETDA and $0.02 \%$ sodium azide) and then labelled with antibodies to identify the dendritic cells (Table 4). Cells were fixed in $1 \%$ paraformaldehyde (PFA) if only surface markers were examined.

For intracellular cytokine analysis, cells were fixed using Leucoperm A buffer (Bio-Rad) and permeabilised using Leucoperm B (Bio-Rad) and then labelled with antibodies to interleukin (IL)-10 and IL-6 (Table 4). Finally, cells were fixed again in $1 \%$ PFA and stored at $4{ }^{\circ} \mathrm{C}$.

\section{Flow cytometry}

Single-cell suspensions were acquired on the BD FACSCanto II (BD Biosciences) or the BD LSR Fortessa (BD Biosciences). Compensation was carried out on FACS Diva software using Anti-Mouse Ig, $\mathrm{K} /$ Negative Control Compensation Particles Set (BD Biosciences) conjugated to antibodies used in above labelling experiments. The $\mathrm{ArC}^{\mathrm{Tm}}$ Amine Reactive Compensation Bead Kit (Thermo Fisher Scientific) was used for compensation of the LIVE/DEAD ${ }^{\text {tw }}$ Fixable Near-IR Dead Cell Stain according to kit instructions. Data analysis was done using the FlowJo_v.10 software.

\section{Cytokine bead array}

The LEGENDplex Human Inflammation Panel I (Biolegend, London, UK ) was used to simultaneously quantify 13 human cytokines/chemokines (IL- $1 \beta$, IFN- $\alpha 2$, IFN- $\gamma$, TNF- $\alpha$, MCP-1 (CCL2), IL-6, IL-8 (CXCL8), IL-10, IL12p70, IL-17A, IL-18, IL-23, and IL-33) in biopsy tissue lysates according to the manufacturer's instructions and analysed on a BD LSR Fortessa using the PE and APC channels. Data were analysed using the LEGENDplex data analysis software (Biolegend, London, UK). All cytokines/chemokines were detectable apart from IFN- $\alpha 2$ which was below detection limits.

\section{ELISA}

PBMC were cultured with $\mathrm{Bt}$ or Bt OMVs as described above and cell supernatants were taken at $20 \mathrm{~h}$ post- 
Table 4 Antibodies used for FACS

\begin{tabular}{|c|c|c|c|c|}
\hline Antigen & Clone & Isotype & Fluorochrome & Supplier \\
\hline $\mathrm{CD} 3$ & UCHT1 & $\operatorname{lgG} 1, \mathrm{k}$ & PE Cy5 & BD Bioscience \\
\hline CD14 & 61D3 & $\operatorname{lgG} 1, k$ & PE Cy5 & BioRad-Serotec \\
\hline CD14 & M5E2 & $\lg G 2 a, k$ & PerCP Cy5.5 & BD Bioscience \\
\hline CD14 & МФР9 & $\lg G 2 b, k$ & PECF594 & BD Horizon \\
\hline CD16 & $3 \mathrm{G} 8$ & $\operatorname{lgG} 1, \mathrm{k}$ & PE Cy5 & BD Bioscience \\
\hline CD19 & HIB19 & $\operatorname{lgG} 1, k$ & PE Cy5 & BD Bioscience \\
\hline CD34 & 581 & $\operatorname{lgG} 1, \mathrm{k}$ & PE Cy5 & BD Bioscience \\
\hline CD64 & 10.1 & $\lg G 1, k$ & PerCP Cy5.5 & BD Bioscience \\
\hline CD64 & 10.1 & $\operatorname{lgG} 1, \mathrm{k}$ & PE Cy5 & Abcam \\
\hline CD123 & $6 \mathrm{H} 6$ & $\lg G 1, k$ & PE Cy7 & eBioscience \\
\hline HLA-DR & G46-6 & $\lg G 2 a$ & APC & BD Bioscience \\
\hline HLA-DR & L234 & $\lg G 2 a$ & BV421 & Biolegend \\
\hline HLA-DR & L234 & $\lg G 2 a$ & BV570 & Biolegend \\
\hline CD11c & B-Ly6 & $\operatorname{lgG} 1, \mathrm{k}$ & BV605 & BD Bioscience \\
\hline CD40 & $L O B 7 / 6$ & $\lg G 2 a$ & FITC & AbD Serotec (Bio-Rad) \\
\hline CD40 & $5 C 3$ & $\lg G 1$ & BV711 & BD Bioscience \\
\hline CD45 & $\mathrm{H} 130$ & $\operatorname{lgG} 1, \mathrm{k}$ & BUV395 & BD Horizon \\
\hline CD80 & L307.4 & $\operatorname{lgG} 1, \mathrm{k}$ & FITC & BD Bioscience \\
\hline CD80 & L307.4 & $\operatorname{lgG} 1, \mathrm{k}$ & $P E$ & BD Bioscience \\
\hline CD86 & BU63 & $\lg G 1$ & FITC & AbD Serotec (Bio-Rad) \\
\hline CD86 & $2331(\mathrm{FUN}-1)$ & $\operatorname{lgG} 1, \mathrm{k}$ & AlexaFluor700 & BD Pharmingen \\
\hline CD103 (Integrin aE) & Ber-Act8 & $\lg G 1, k$ & BV421 & Biolegend, BD Bioscience \\
\hline IL-6 & MQ2-13A5 & $\operatorname{lgG} 1, \mathrm{k}$ Rat & FITC & Biolegend \\
\hline IL-6 & MQ2-13A5 & $\operatorname{lgG} 1, \mathrm{k}$ Rat & PE & eBioscience \\
\hline IL-10 & JES-19F1 & $\operatorname{lgG} 1, \mathrm{k}$ Rat & PE & Biolegend \\
\hline $\mathrm{IL}-10$ & JES-19F1 & $\operatorname{lgG} 1, \mathrm{k}$ Rat & APC & BD Bioscience/Biolegend \\
\hline Integrin $\beta 7$ & FIB504 & IgG2a, Rat & PE & Biolegend \\
\hline Integrin $\beta 7$ & FIB504 & IgG2a, Rat & FITC & Biolegend \\
\hline Integrin $\beta 7$ & FIB504 & IgG2a, Rat & APC & BD Bioscience \\
\hline SIRPa (CD172a/b) & SE5A5 & $\operatorname{lgG} 1, \mathrm{k}$ & PECy7 & Biolegend \\
\hline
\end{tabular}

List of all antibodies used to identify and characterise human DC in circulation and in colon for Figs. 1, 2, 3, 4 and 5 and Supplementary Figs 1-4

stimulation and stored at $-80^{\circ} \mathrm{C}$. Amounts of cytokines (IL-6 and IL-10) were measured using Human DuoSet ELISA kits ( $\mathrm{R}$ and $\mathrm{D}$ systems) according to the manufacturer's instructions. Plates were read on the Tecan Infinite F50 plate reader and data were analysed using the Magellan $^{\mathrm{TM}}$ software (Tecan Group Ltd, Mannedorf, Switzerland).

\section{Statistical analysis}

Statistical analysis was carried out using the GraphPad Prism software version 8. For in vitro experiments, data were analysed using nonparametric Mann-Whitney $U$ tests (Fig. $1 \mathrm{~b}$ and Supplementary Figure 1a); unpaired $t$ tests (Fig. 3); ordinary one-way ANOVA with Dunnett's multiple comparisons test
(Figs. 1d and 2b, d (IL-10), Fig. 5b and Supplementary Figure 2B), one-way ANOVA with Brown-Forsyth and Welch corrections for unequal variance with Dunnett's T3 multiple comparisons test (Figs. 2c and $4 \mathrm{a}, \mathrm{b})$ or non-parametric Kruskal-Wallis ANOVA with Dunn's multiple comparisons test (Figs. $1 \mathrm{e}$ and $2 \mathrm{~d}$ (IL-6) and Fig. 4c) when making comparisons between experimental conditions within a single group; or ordinary two-way ANOVA with Holm's Sidak's multiple comparisons test (Figs. 4 and 5) for making comparisons between groups for different experimental conditions. Colonic LP DC data from HC, CD and UC patients (Supplementary Figure 3) were analysed using non-parametric Kruskal-Wallis ANOVA with Dunn's multiple comparisons test; " $p<0.05$. 


\section{Supplementary information}

Supplementary information accompanies this paper at https://doi.org/10. 1186/s40168-020-00868-z.

Additional file 1: Supplementary Figure 1. Bt OMVs induce diverse cytokines from whole colon tissue and marked $\mathrm{L}$-10 response from colonic LP mDC. Supplementary Figure 2. Plasmacytoid DC cytokine response to Bt and Bt OMVs in healthy controls. Supplementary Figure 3. Loss of $C D 103^{+}$DC in UC and CD colonic LP. Supplementary Figure 4. Bt OMVs do not induce $I L-10$-expressing $\mathrm{mDC}$ in colonic LP in ulcerative colitis.

\section{Abbreviations}

Bt: Bacteroides thetaiotaomicron; OMVs: Outer membrane vesicles; DC: Dendritic cells; CD: Crohn's disease; UC: Ulcerative colitis; IL: Interleukin; IBD: Inflammatory bowel disease; Gl: Gastrointestinal; pIVOC: Polarised in vitro culture system; Pn: Prevotella nanceiensis; HC: Healthy control; LP: Lamina propria; PBMC: Peripheral blood mononuclear cells; mDC: Myeloid dendritic cell; pDC: Plasmacytoid dendritic cell; Th: T helper; Bf: Bacteroides fragilis; SIRPa: Signal regulatory protein alpha; CD103: Integrin alpha E; cDC: Conventional dendritic cell; TI: Terminal ileum; PSA: Capsular polysaccharide A

\section{Acknowledgements}

We thank Kathryn Cross for her assistance with scanning electron microscopy.

\section{Authors' contributions}

L.D., R.S., A.N., S.C.K. and S.R.C. designed the studies and wrote the manuscript. J.B. and N.G. designed studies, performed experiments and analysed data pertaining to whole biopsy culture experiments shown in Fig. $1 \mathrm{~b}$ and Supplementary Figure 1a. L.D. performed experimental work and analysed the data pertaining to all other figures. A.N., D.R., M.J.O., P.H., E.T.P. and S.D. assisted with experimental work and data interpretation. R.S. isolated Bt and Pn OMVs, prepared OMVs for electron microscopy experiments and provided OMV expertise. L.H. and A.M. isolated all other commensal bacteria strains and provided microbiota expertise. J.B., R.M., J.S., E.T.P., S.D., P.H., J.P.S., D.L., R.M., A.L.H. and N.A. recruited patients and provided clinical samples. J.B., S.D., E.T.P., A.L.H. and N.A. provided clinical inputs on the study. All authors provided inputs on the manuscript.

\section{Funding}

We acknowledge the support of the Biotechnology and Biological Sciences Research Council (BBSRC); this research was funded by the Quadram Institute Gut Health and Food Safety Strategic Programme BB/J004529/1 and the BBSRC Institute Strategic Programme Gut Microbes and Health BB/R012490/1 and its constituent projects BBS/E/F/000PR10353 and BBS/E/F/000PR10356 (S.R.C.). Funding for A.N. and S.C.K. was from London North West University Healthcare NHS Trust R\&D. L.H. was in receipt of an MRC Intermediate Research Fellowship (grant number MR/L01632X/1, UK Med-Bio).

\section{Availability of data and materials}

The datasets used and/or analysed during the current study are available from the corresponding author on reasonable request.

\section{Ethics approval and consent to participate}

Ethics approval was obtained from the Health Research Authority UK and London Brent Research Ethics Committee. Written informed consent was received from participants prior to inclusion in the study. For whole biopsy culture experiments, ethics approval was obtained from the University of East Anglia Faculty of Medicine and Health Sciences Ethics Committee and Human Tissue Act Subcommittee ref 20152016-39HT and the Norfolk and Norwich University Hospital Research and Development Committee ref 2001-16.

\section{Consent for publication}

Not applicable

\section{Competing interests}

The authors declare that they have no competing interests.

\section{Author details}

Antigen Presentation Research Group, Imperial College London, Northwick Park \& St. Mark's Hospital Campus, Watford Rd, Harrow, Greater London HA1 3UJ, UK. ${ }^{2}$ Gut Microbes and Health Research Programme, Quadram Institute Bioscience, Norwich NR4 7UQ, UK. ${ }^{3}$ Norwich Medical School, University of East Anglia, Norwich NR4 7TJ, UK. ${ }^{4}$ Department of Biosciences, Nottingham Trent University, Clifton Campus, Nottingham NG11 8NS, UK. ${ }^{5}$ Food Microbial Sciences Unit, University of Reading, Whiteknights, Reading RG6 6UR, UK. ${ }^{6} \mathrm{St}$ Mark's Hospital, London North West University Healthcare NHS Trust, Harrow, Greater London HA1 3UJ, UK.

Received: 17 December 2019 Accepted: 13 May 2020

Published online: 08 June 2020

\section{References}

1. Sender R, Fuchs S, Milo R. Revised estimates for the number of human and bacteria cells in the body. PLOS Biol. 2016;14:e1002533.

2. Luckey TD. Introduction to intestinal microecology. Am. J. Clin. Nutr. 1972; 25:1292-4.

3. Thursby $\mathrm{E}$, Juge N. Introduction to the human gut microbiota. Biochem. J. 2017:474:1823-36

4. Moore WE, Holdeman LV. Human fecal flora: the normal flora of 20 Japanese-Hawaiians. Appl. Microbiol. 1974;27:961-79.

5. Human Microbiome Consortium Project. Structure, function and diversity of the healthy human microbiome. Nature. 2012;486:207-14.

6. Eckburg PB. Diversity of the human intestinal microbial flora. Science (80-. ). 2005;308:1635-8.

7. Wrzosek L, et al. Bacteroides thetaiotaomicron and Faecalibacterium prausnitzii influence the production of mucus glycans and the development of goblet cells in the colonic epithelium of a gnotobiotic model rodent. BMC Biol. 2013;11:61.

8. Hooper LV. Molecular analysis of commensal host-microbial relationships in the intestine. Science (80-. ). 2001:291:881-4.

9. Kelly $D$, et al. Commensal anaerobic gut bacteria attenuate inflammation by regulating nuclear-cytoplasmic shuttling of PPAR- $\gamma$ and RelA. Nat. Immunol. 2004;5:104-12.

10. Bloom SM, et al. Commensal bacteroides species induce colitis in hostgenotype-specific fashion in a mouse model of inflammatory bowel disease. Cell Host Microbe. 2011:9:390-403.

11. Delday M, Mulder I, Logan ET, Grant G. Bacteroides thetaiotaomicron ameliorates colon inflammation in preclinical models of Crohn's disease. Inflamm. Bowel Dis. 2019;25:85-96.

12. Elhenawy W, Debelyy MO, Feldman MF. Preferential packing of acidic glycosidases and proteases into bacteroides outer membrane vesicles. MBio. 2014:5:e00909-14.

13. Chatterjee SN, Das J. Electron microscopic observations on the excretion of cell-wall material by Vibrio cholerae. J. Gen. Microbiol. 1967;49:1-11.

14. Kaparakis-Liaskos M, Ferrero RL. Immune modulation by bacterial outer membrane vesicles. Nat. Rev. Immunol. 2015;15:375-87.

15. Bryant WA, et al. In silico analysis of the small molecule content of oute membrane vesicles produced by Bacteroides thetaiotaomicron indicates an extensive metabolic link between microbe and host. Front. Microbiol. 2017; $8: 2440$.

16. Jacobson AN, Choudhury BP, Fischbach MA. The biosynthesis of lipooligosaccharide from Bacteroides thetaiotaomicron. MBio. 2018;9:e0228917.

17. Stentz R, Carvalho AL, Jones EJ, Carding SR. Fantastic voyage: the journey of intestinal microbiota-derived microvesicles through the body. Biochem. Soc. Trans. 2018:46:1021-7.

18. Alves NJ, Turner KB, Medintz IL, Walper SA. Protecting enzymatic function through directed packaging into bacterial outer membrane vesicles. Sci. Rep. 2016;6:24866

19. Devoe IW. RELEASE OF ENDOTOXIN IN THE FORM OF CELL WALL BLEBS DURING IN VITRO GROWTH OF NEISSERIA MENINGITIDIS. J. Exp. Med. 1973; 138:1156-67.

20. DeVoe I. Pili on meningococci from primary cultures of nasopharyngeal carriers and cerebrospinal fluid of patients with acute disease. J. Exp. Med. 1975;141:297-305

21. Fiocca $R$, et al. Release of Helicobacter pylori vacuolating cytotoxin by both a specific secretion pathway and budding of outer membrane vesicles. 
Uptake of released toxin and vesicles by gastric epithelium. J. Pathol. 1999; 188:220-6.

22. Ren $\mathrm{D}$, et al. Characterization of extended co-culture of non-typeable Haemophilus influenzae with primary human respiratory tissues. Exp. Biol. Med. 2012;237:540-7.

23. Shen $\mathrm{Y}$, et al. Outer membrane vesicles of a human commensal mediate immune regulation and disease protection. Cell Host Microbe. 2012;12:509-20.

24. Hickey CA, et al. Colitogenic Bacteroides thetaiotaomicron antigens access host immune cells in a sulfatase-dependent manner via outer membrane vesicles. Cell Host Microbe. 2015;17:672-80.

25. Stentz $R$, et al. A bacterial homolog of a eukaryotic inositol phosphate signaling enzyme mediates cross-kingdom dialog in the mammalian gut. Cell Rep. 2014;6:646-56.

26. Oster $P$, et al. MeNZB?: a safe and highly immunogenic tailor-made vaccine against the New Zealand serogroup B disease epidemic strain. Vaccine. 2005;23:2191-6.

27. Gerritzen MJH, Martens DE, Wijfels RH, van der Pol L, Stork M. Bioengineering bacterial outer membrane vesicles as vaccine platform. Biotechnol. Adv. 2017;35:565-74.

28. Carvalho AL, et al. Use of bioengineered human commensal gut bacteriaderived microvesicles for mucosal plague vaccine delivery and immunization. Clin. Exp. Immunol. 2019;196:287-304.

29. Carvalho AL, et al. Bioengineering commensal bacteria-derived outer membrane vesicles for delivery of biologics to the gastrointestinal and respiratory tract. J. Extracell. Vesicles. 2019;8:1632100.

30. Ng SC, et al. Worldwide incidence and prevalence of inflammatory bowel disease in the 21st century: a systematic review of population-based studies. Lancet. 2017;390:2769-78.

31. Geremia A, Biancheri P, Allan P, Corazza GR, Di Sabatino A. Innate and adaptive immunity in inflammatory bowel disease. Autoimmun. Rev. 2014; 13:3-10.

32. Mann ER, et al. Intestinal dendritic cells: their role in intestinal inflammation, manipulation by the gut microbiota and differences between mice and men. Immunol. Lett. 2013;150:30-40.

33. Magnusson MK, et al. Macrophage and dendritic cell subsets in IBD: ALDH+ cells are reduced in colon tissue of patients with ulcerative colitis regardless of inflammation. Mucosal Immunol. 2016;9:171-82.

34. Mann ER, et al. Human gut dendritic cells drive aberrant gut-specific T-cell responses in ulcerative colitis, characterized by increased IL-4 production and loss of IL-22 and IFNy. Inflamm. Bowel Dis. 2014;20:2299-307.

35. Hegazy AN, et al. Circulating and tissue-resident CD4 + T cells with reactivity to intestinal microbiota are abundant in healthy individuals and function is altered during inflammation. Gastroenterology. 2017;153:13201337.e16.

36. Noble A, et al. Deficient resident memory T-cell and $\mathrm{Cd} 8 \mathrm{~T}$-cell response to commensals in inflammatory bowel disease. J. Crohn's Colitis. 2019. https:// doi.org/10.1093/ecco-jcc/jjz175.

37. Ni J, Wu GD, Albenberg L, Tomov VT. Gut microbiota and IBD: causation or correlation? Nat. Rev. Gastroenterol. Hepatol. 2017;14:573-84.

38. Kühn R, Löhler J, Rennick D, Rajewsky K, Müller W. Interleukin-10-deficient mice develop chronic enterocolitis. Cell. 1993;75:263-74.

39. Spencer SD, et al. The orphan receptor CRF2-4 is an essential subunit of the interleukin 10 receptor. J. Exp. Med. 1998;187:571-8.

40. Zigmond E, et al. Macrophage-restricted interleukin-10 receptor deficiency, but not IL-10 deficiency, causes severe spontaneous colitis. Immunity. 2014; 40:720-33.

41. Shouval DS, et al. Interleukin-10 receptor signaling in innate immune cells regulates mucosal immune tolerance and anti-inflammatory macrophage function. Immunity. 2014;40:706-19.

42. Girard-Madoux MJH, et al. IL-10 control of CD11C + myeloid cells is essential to maintain immune homeostasis in the small and large intestine. Oncotarget. 2016;7(22):32015-30

43. Glocker E-O, et al. Inflammatory bowel disease and mutations affecting the interleukin-10 receptor. N. Engl. J. Med. 2009;361:2033-45.

44. Pigneur B, et al. Phenotypic characterization of very early-onset IBD due to mutations in the IL10, IL10 receptor alpha or beta gene. Inflamm. Bowel Dis. 2013;19:2820-8

45. Begue $B$, et al. Defective IL10 signaling defining a subgroup of patients with inflammatory bowel disease. Am. J. Gastroenterol. 2011;106:1544-55.

46. de Smedt T, et al. Effect of interleukin-10 on dendritic cell maturation and function. Eur. J. Immunol. 1997;27:1229-35.
47. Loschko J, et al. Absence of MHC class II on CDCs results in microbialdependent intestinal inflammation. J. Exp. Med. 2016;213(4):517-34.

48. Stagg AJ, Hart AL, Knight SC, Kamm MA. Interactions between dendritic cells and bacteria in the regulation of intestinal immunity. Best Pract. Res. Clin. Gastroenterol. 2004;18:255-70.

49. Coombes JL, et al. A functionally specialized population of mucosal CD103 + DCs induces Foxp3 + regulatory T cells via a TGF- $\beta$ - and retinoic aciddependent mechanism. J. Exp. Med. 2007;204:1757-64.

50. Sun C-M, et al. Small intestine lamina propria dendritic cells promote de novo generation of Foxp3 T reg cells via retinoic acid. J. Exp. Med. 2007;204: 1775-85.

51. Al-Hassi $\mathrm{HO}$, et al. Altered human gut dendritic cell properties in ulcerative colitis are reversed by Lactobacillus plantarum extracellular encrypted peptide STp. Mol. Nutr. Food Res. 2014;58:1132-43.

52. Mann ER, et al. Dysregulated circulating dendritic cell function in ulcerative colitis is partially restored by probiotic strain Lactobacillus casei Shirota. Mediators Inflamm. 2013:2013:1-12

53. Stentz R, et al. Cephalosporinases associated with outer membrane vesicles released by Bacteroides spp. protect gut pathogens and commensals against $\beta$-lactam antibiotics. J. Antimicrob. Chemother. 2015;70:701-9.

54. Watchmaker PB, et al. Comparative transcriptional and functional profiling defines conserved programs of intestinal DC differentiation in humans and mice. Nat. Immunol. 2014;15:98-108.

55. Bernardo D, et al. Chemokine (C-C Motif) receptor 2 mediates dendritic cell recruitment to the human colon but is not responsible for differences observed in dendritic cell subsets, phenotype, and function between the proximal and distal colon. Cell. Mol. Gastroenterol. Hepatol. 2016;2:22-39.e5.

56. Mann ER, et al. Compartment-specific immunity in the human gut: properties and functions of dendritic cells in the colon versus the ileum. Gut. 2016;65:256-70

57. Larsen JM, et al. Chronic obstructive pulmonary disease and asthmaassociated Proteobacteria, but not commensal Prevotella spp., promote tolllike receptor 2-independent lung inflammation and pathology. Immunology. 2015;144:333-42.

58. Larsen JM. The immune response to Prevotella bacteria in chronic inflammatory disease. Immunology. 2017;151:363-74.

59. Xu J. A genomic view of the human-Bacteroides thetaiotaomicron symbiosis. Science (80-. ). 2003;299:2074-6.

60. Jones, E. J. et al. The uptake, trafficking and biodistribution of Bacteroides thetaiotaomicron generated outer membrane vesicles. Front. Microbiol. In Press, (2020).

61. Tanaka, T., Narazaki, M. \& Kishimoto, T. IL-6 in inflammation, immunity, and disease. Cold Spring Harb. Perspect. Biol. 6, a016295-a016295 (2014).

62. Tanaka T, Kishimoto T. The biology and medical implications of interleukin6. Cancer Immunol. Res. 2014;2:288-94.

63. Waldner MJ, Neurath MF. Master regulator of intestinal disease: IL-6 in chronic inflammation and cancer development. Semin. Immunol. 2014;26: 75-9.

64. Bernardo $D$, et al. IL-6 promotes immune responses in human ulcerative colitis and induces a skin-homing phenotype in the dendritic cells and T cells they stimulate. Eur. J. Immunol. 2012;42:1337-53.

65. de Waal Malefyt R, Abrams J, Bennett B, Figdor CG, de Vries JE. Interleukin 10 (IL-10) inhibits cytokine synthesis by human monocytes: an autoregulatory role of IL-10 produced by monocytes. J. Exp. Med. 1991;174: $1209-20$.

66. Fiorentino DF, Zlotnik A, Mosmann TR, Howard M, O'Garra A. IL-10 inhibits cytokine production by activated macrophages. J. Immunol. 1991;147:381522.

67. Saraiva M, Vieira P, O'Garra A. Biology and therapeutic potential of interleukin-10. J. Exp. Med. 2020;217:e20190418.

68. Da Silva S, et al. A novel topical PPARy agonist induces PPARY activity in ulcerative colitis mucosa and prevents and reverses inflammation in induced colitis models. Inflamm. Bowel Dis. 2018;24:792-805.

69. Sitkin, S. \& Pokrotnieks, J. Gut microbiota as a host defender and a foe: the 2 faces of commensal Bacteroides thetaiotaomicron in inflammatory bowel disease. Inflamm. Bowel Dis. 25, e71-e71 (2019).

70. Veenbergen $\mathrm{S}$, et al. IL-10 signaling in dendritic cells controls IL-1 $1 \beta$ mediated IFNy secretion by human CD4+ T cells: relevance to inflammatory bowel disease. Mucosal Immunol. 2019;12:1201-11. 
71. Huber S, et al. Th17 cells express interleukin-10 receptor and are controlled by Foxp3- and Foxp3+ regulatory CD4+ T cells in an interleukin-10dependent manner. Immunity. 2011;34:554-65.

72. Liu B, Tonkonogy SL, Sartor RB. Antigen-presenting cell production of IL-10 inhibits T-Helper 1 and 17 cell responses and suppresses colitis in mice. Gastroenterology. 2011;141:653-662.e4.

73. Edwards LA, et al. Aberrant response to commensal Bacteroides thetaiotaomicron in Crohn's disease. Inflamm. Bowel Dis. 2011;17:1201-8

74. Hoyles $L$, et al. Klebsiella pneumoniae subsp. pneumoniae-bacteriophage combination from the caecal effluent of a healthy woman. PeerJ. 2015;3: e1061.

75. Hoyles $\mathrm{L}$, et al. Metabolic retroconversion of trimethylamine $\mathrm{N}$-oxide and the gut microbiota. Microbiome. 2018:6:73.

76. Thorasin T, Hoyles L, McCartney AL. Dynamics and diversity of the 'Atopobium cluster' in the human faecal microbiota, and phenotypic characterization of 'Atopobium cluster' isolates. Microbiology. 2015;161:56579 .

77. Schüller S, Lucas M, Kaper JB, Girón JA, Phillips AD. The ex vivo response of human intestinal mucosa to enteropathogenic Escherichia coli infection. Cell. Microbiol. 2009;11:521-30

\section{Publisher's Note}

Springer Nature remains neutral with regard to jurisdictional claims in published maps and institutional affiliations.

Ready to submit your research? Choose BMC and benefit from:

- fast, convenient online submission

- thorough peer review by experienced researchers in your field

- rapid publication on acceptance

- support for research data, including large and complex data types

- gold Open Access which fosters wider collaboration and increased citations

- maximum visibility for your research: over $100 \mathrm{M}$ website views per year

At BMC, research is always in progress.

Learn more biomedcentral.com/submissions 